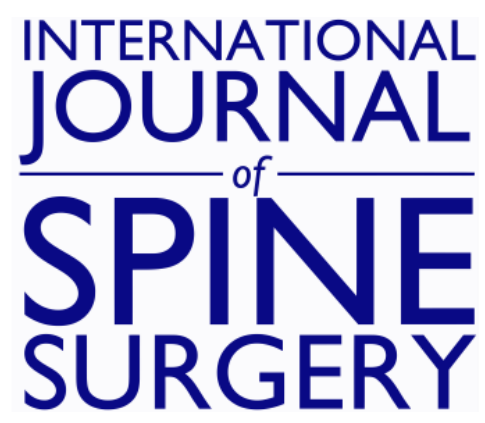

\title{
Analysis of the Variables Affecting the Incidence, Location, and Severity of Cage Subsidence Following Anterior Cervical Discectomy and Fusion Operation
}

ANDREW P. MACCORMICK and HIMANSHU SHARMA

Int J Spine Surg 2020, 14 (6) 896-900

doi: https://doi.org/10.14444/7137

http://ijssurgery.com/content/14/6/896

This information is current as of April 26, 2023.

Email Alerts Receive free email-alerts when new articles cite this article. Sign up at:

http://ijssurgery.com/alerts

The International Journal of Spine Surgery

2397 Waterbury Circle, Suite 1,

Aurora, IL 60504, Phone: +1-630-375-1432 


\title{
Analysis of the Variables Affecting the Incidence, Location, and Severity of Cage Subsidence Following Anterior Cervical Discectomy and Fusion Operation
}

\author{
ANDREW P. MACCORMICK, BMBS, HIMANSHU SHARMA \\ South West Neurosurgery Centre, Derriford Hospital, Plymouth, United Kingdom
}

\begin{abstract}
Background: For surgical management of degenerative cervical spine disease with myeloradiculopathy, standalone cages are frequently used in 1- and 2-level anterior cervical discectomy and fusion (ACDF) operations with a paucity of literature on factors influencing cage subsidence. The aim of this study was to analyze the variables affecting the incidence, location, and severity of cage subsidence.

Methods: Retrospective review of prospectively collected data of 77 patients ( 95 levels) undergoing ACDF surgery was conducted. Variables analyzed were age, gender, sagittal alignment, maximum disc height (superior, inferior, and procedure levels), cage size, shape, location, degree of subsidence (minor $<2 \mathrm{~mm}$, mild $2-4 \mathrm{~mm}$, moderate 5-7.5 mm, severe $>7.5 \mathrm{~mm}$ ) and location of subsidence.

Results: The incidence of cage subsidence was 34\% (32 levels), and 91\% were minor or mild. Significantly lower mean maximum height of the inferior disc compared to the nonsubsidence group $(5.17$ versus $5.96 ; P=0.0025)$ was recorded. Significantly greater incidence of subsidence $(40 \%)$ was recorded in patients with abnormal cervical spine alignment (focal or diffuse kyphosis) versus $18 \%$ with normal alignment $(P=0.02)$. Greater incidence of subsidence was recorded with more anterior positioned cages $(52 \% ; \mathrm{p}=0.01)$. No statistical significance was found for age, gender, superior disc height, or cage shape/size.

Conclusions: Greater incidence of cage subsidence is significantly associated with a lower maximum disc height of the disc below the operated level $(<5.5 \mathrm{~mm})$, abnormal sagittal alignment, and more anteriorly positioned cages. We found that the vast majority of cage subsidence was focal, minor to mild, without having any immediate or late clinical implications in terms of need for revision surgery.
\end{abstract}

Cervical Spine

Keywords: subsidence, ACDF, myelopathy, radiculopathy, complication

\section{BACKGROUND}

With cervical spondylosis and related disorders becoming increasing prevalent in Western countries ${ }^{1}$, further focus is required in the management of these conditions for obtaining better outcomes. Surgical intervention is often required if persisting and/or progressive neurological deficit (myeloradiculopathy) occurs with disc herniation or disc osteophyte complex visible on magnetic resonance imaging scans. ${ }^{2}$

Treatment options for these patients range from simple discectomy, discectomy with fusion, and cervical disc arthroplasty. Smith and Robinson ${ }^{3}$ introduced anterior cervical discectomy and fusion (ACDF) in the late 1950s, and it has since become the gold standard surgical procedure for the management of degenerative cervical spinal disease with myeloradiculopathy. ${ }^{4}$ This procedure is most frequently performed at 1 or 2 levels using standalone cages during the ACDF procedure. ${ }^{5}$

Intervertebral cage subsidence may have clinical implications when using stand-alone cages in both single- and multilevel disease. ${ }^{6}$ Subsidence may be caused by a multitude of factors, and there is currently a limited amount of evidence in the literature regarding the causation and prognostic significance of subsidence. ${ }^{7}$ Despite the high incidence of subsidence, its clinical relevance remains unknown. ${ }^{8}$ The purpose of this study was to analyze the variables affecting the incidence, location, and severity of cage subsidence following ACDF operation.

\section{METHODS}

A retrospective review of prospectively collected data of 77 consecutive patients (95 levels) undergo- 
ing ACDF was conducted. These procedures were performed between 2013 and 2017 by the single operating surgeon, and the operations were performed between the levels of $\mathrm{C} 3$ and $\mathrm{C} 7$. The mean postoperative follow-up was 10 months.

The operative technique involved the patient being in the supine position, and a right-sided 4-6$\mathrm{cm}$ transverse incision was made. The SmithPatterson approach was used between the tissue planes with medial retraction of the tracheooesophageal complex and lateral retraction of carotid sheath contents. Complete discectomy and unco-vertebral decompression was performed along with a posterior longitudinal ligament takedown. A cage size was then selected and trialed before the appropriate size cage was used. The cages used were either Rabea or Cervios-Synthes, and the sizes ranged from 5 to $7 \mathrm{~mm}$. Intraoperative $\mathrm{x}$-rays were taken for level check, adequacy of implant size, and position. Wound drainage was then used in the majority of cases, and patients were asked to keep a soft cervical collar on postoperatively for between 4 and 6 weeks. The average hospital stay after the procedure was between 1 and 2 days; however, myelopathic patients stayed longer.

Indications for surgery included persistent or progressive compressive myelopathy and/or radiculopathy resulting from 1- or 2-level cervical degenerative disc disease. The variables analyzed were age, gender, sagittal alignment, maximum disc height (superior, inferior, and procedure levels), cage size, shape, location, degree of subsidence (mild or minor $<2 \mathrm{~mm}$, moderate $2-4 \mathrm{~mm}$, severe $>5 \mathrm{~mm}$ ), location of subsidence, and progression of subsidence on serial radiographs. Location of the cage was calculated using both the distance between the anterior border of the cage and the anterior vertebral line and also the distance between the posterior border of the cage and the posterior vertebral line.

Routine antero-posterior and lateral $\mathrm{x}$-rays were taken pre- and postoperatively during the 2 followup clinic appointments (first follow-up at 6-10 weeks, second follow-up at 6-10 months). All patients had at least 2 postoperative x-rays. These were analyzed for fusion process and any cagerelated problems. The x-rays were stored and accessed via the picture archive and communicating system (PACS) software. The x-ray taken at the 610 -month follow-up was the one used to define the presence of subsidence.

Cervical spine alignment was calculated on cervical spine $\mathrm{x}$-ray using the Cobb angle between

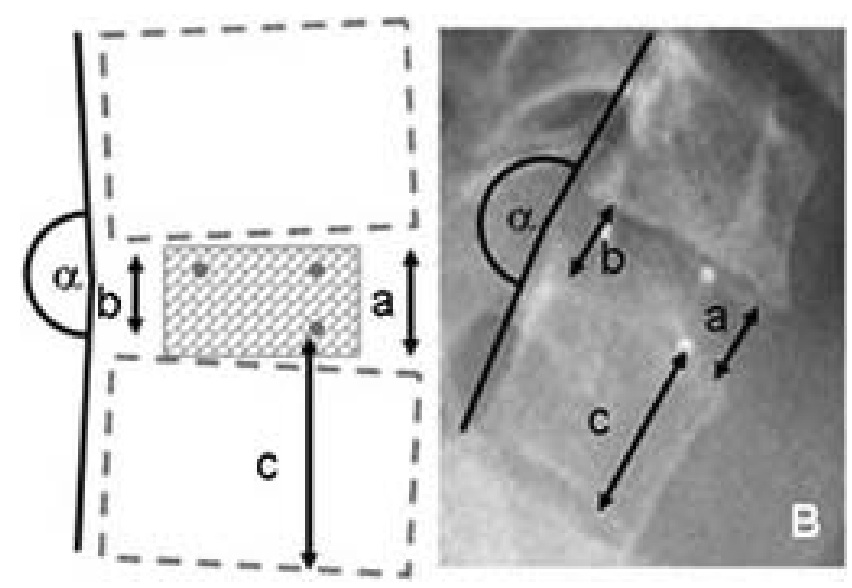

Figure 1. Measurement of cage subsidence.

$\mathrm{C} 2$ and $\mathrm{C} 7$. The cervical spine alignment was then defined as either normal, loss of lordosis, or a kyphosis. Those patients who were found to have a kyphosis were then split into those who had a focal area and those who had diffuse kyphosis.

Subsidence was defined as per previously described methods, which included measuring the anterior disc height and posterior disc height and using the distance between the inferior border of the inferior vertebra from the inferior border of the cage and comparing this over serial plain radiographs (Figure 1). ${ }^{9}$ When analyzing cage subsidence, we looked into whether subsidence was monofocal (whether it involved either superior or inferior endplates) or bifocal (whether it involved both superior and inferior endplates). In addition, we evaluated whether the subsidence was localized or diffuse in nature. Any migration of the cage was noted if there was any anterior or posterior migration as well as examining any loosening of the cage.

\section{Statistical Analysis}

SPSS software was used for the statistical analysis of study data. A $P$ value of $<.05$ was considered to be statistically significant. Data were expressed as mean values with standard deviations for continuous variables and numbers in percentage form for categorical variables. Statistical significance was measured between groups using 2 independentsample $t$ tests for continuous variables and the Fisher exact test for categorical variables.

\section{RESULTS}

There were 77 consecutive patients (95 levels) included in this study. The majority of the patients 
$(59 / 77 ; 76.6 \%)$ had 1 -level surgery, with the remaining $(18 / 77 ; 23.3 \%)$ having 2-level ACDF procedures. The mean age of the patients was 58 years (range $27-83$ years) with $16(21 \%)$ being over the age of 65 years. There were 48 males and 29 females included.

At final follow-up on plain radiographs, the overall incidence of cage subsidence was 34\% (32/ 95 levels). Of these 32 levels, the majority of the subsidence was between 2 and $4 \mathrm{~mm}(20 / 32,63 \%)$ with another 9 levels $(28 \%)$ showing subsidence of less than $2 \mathrm{~mm}$ and only 3 levels (9\%) with subsidence of over $5 \mathrm{~mm}$.

When comparing subsidence incidence with cervical spinal alignment, a significantly greater incidence of subsidence was recorded in patients with abnormal cervical spine alignment compared with normal alignment (40\% versus $18 \%(P=.02)$.

A significantly greater incidence of subsidence was recorded with anteriorly positioned cages compared with central or posteriorly positioned cages $(52 \%$ versus $25 \%(P=.01)$.

When comparing the subsidence group to the nonsubsidence group, a significantly lower mean maximum height of the inferior disc was found in the subsidence group (5.17 versus 5.96; $P=.0025$ ).

No statistical significance was found when comparing the incidence of subsidence with age, gender, superior disc height, cage shape, and size. None of the patients required revision operation for subsidence.

\section{DISCUSSION}

Cage subsidence following 1- or 2-level ACDF using stand-alone cages could occur in $34 \%$ of cases, and the vast majority $(91 \%)$ of them could be minor to mild. None of the patients needed revision surgery, highlighting that such radiological findings may be a natural process of cage consolidation without many clinical implications.

One- or 2-level stand-alone cages are commonly used in clinical practice for the treatment of symptomatic cervical spondylosis and related disorders associated with myelo-radiculopathy. ${ }^{9}$ Moderate to severe cage subsidence could pose a concern if it results in worsening of foraminal stenosis, cervical spine instability, and loss of segmental lordosis with adjacent segment degeneration. ${ }^{10}$

Our study, with patient demographics comparable to those in the current literature, ${ }^{5,8,11}$ has demonstrated that cage subsidence is common and can be impacted by patient factors, such as inferior disc height, and operative factors, such as positioning of the cage. Despite this, no patients required revision surgery as a result of subsidence. The impact that subsidence has on outcomes postoperatively remains unknown from our study and in the current literature. We propose that the increase in subsidence rate in patients with a narrower inferior disc height could be caused by the load transmission through a degenerative disc that has lost disc height and therefore increases focal stress on the cage itself.

Cage subsidence is commonly seen to affect the superior endplate of the inferior vertebra. We commonly observed the occurrence of a small crater (focal subsidence) at the antero-superior endplate of the inferior vertebra. This probably represents a focal stress riser effect with eccentric cage loading over a softened endplate. Careful endplate preparation that avoids endplate violation should be practiced. Note that coexisting cage subsidence and loosening are extremely uncommon. Anterior or posterior cage migration is usually associated with a loosened cage rather than a subsided cage, which could be secondary to a multitude of factors, such as bone quality, adequacy of decompression, use of an undersized cage, and so on. Bone mineral density (underlying osteopenia or osteoporosis) could also have an influence that was not studied here. It appears that minor cage subsidence is a rather natural process of cage incorporation and fusion with weight-bearing forces. It is also apparent that the radiological finding of cage subsidence is not correlated with clinical manifestations. Furthermore, none of the patients with cage subsidence were revised.

In our study, adverse clinical outcomes in terms of worsening neck or arm pain and worsening myelopathic manifestations were not observed in patients with cage subsidence necessitating a revision surgery; however, these were assessed only for any indications for revision surgery and could be assessed in detail in future studies to throw more light on clinical radiological correlation of subsidence, clinical symptoms, and need for a revision procedure.

This study showed that the majority of the subsidence was between 2 and $4 \mathrm{~mm}(20 / 32,63 \%)$ with another 9 levels (28\%) showing subsidence of less than $2 \mathrm{~mm}$ and only 3 levels (9\%) with subsidence of over $5 \mathrm{~mm}$. Although we found no direct clinical implication of focal and minor to mild 
cage subsidence, the impact that this may have on the long-term outcomes for these patients is unknown and is recommended as a focus for future studies. These results emphasize the importance of intraoperative fluoroscopy and serial postoperative $\mathrm{x}$-rays in order to monitor progressively worsening cage subsidence, especially in high-risk patients. If cervical spine malalignment is present or if there is associated cage migration or loosening, then close postoperative monitoring should be stressed.

The increased likelihood of cage subsidence in abnormally aligned cervical spines could be due to the line of gravity passing more anteriorly in a kyphotic cervical spine. We found a significantly greater incidence of subsidence with anteriorly positioned cages compared with central or posteriorly positioned cages $(52 \%$ versus $25 \% ; P=$ $.01)$. While trialing or placing the actual implant, one could aim for more posteriorly placed cages, preferably between 2 and $5 \mathrm{~mm}$ from the posterior vertebral border. Many surgeons do not perform intraoperative x-rays after cage placement. The authors would like to stress here that intraoperative $\mathrm{x}$-rays following cage trial and actual cage placement should be encouraged in order to confirm the adequacy of cage size and exact cage location. Overstuffing of the cage should be avoided for excessive facet joint strain, and malplaced cages could be rectified instantaneously.

When comparing incidence of subsidence with cervical spinal alignment, a significantly greater incidence of subsidence was found in patients with abnormal cervical spine alignment (loss of lordosis or kyphosis) compared with normal alignment $(P=$ $.02)$. Encouraging patients to occupy upright neck posture could help reduce the incidence and progression of cage subsidence, especially during the first 3-4 months postoperatively.

\section{CONCLUSIONS}

This study has shown that cage subsidence is a common complication of ACDF procedures with rates that are similar to those in recent literature. , $8,11^{\text {A }}$ greater incidence of subsidence is significantly associated with patients with abnormal cervical spine sagittal alignment, more anteriorly positioned cages, and a lower maximum disc height of the disc below the operated level $(<5.5 \mathrm{~mm})$. We found that the vast majority of cage subsidence was focal, minor to mild, without having any immediate or late clinical implications or need for revision surgery.

\section{REFERENCES}

1. Roh JS, Teng AL, Yoo JU, Davis J, Furey C, Bohlman HH. Degenerative disorders of the lumbar and cervical spine. Orthop Clin North Am. 2005;36(3):255-262. doi:10.1016/j.ocl. 2005.01.007

2. Gebremariam L, Koes BW, Peul WC, Huisstede BM. Evaluation of treatment effectiveness for the herniated cervical disc: a systematic review. Spine (Phila Pa 1976). 2012;37(2):E109-E118. doi:10.1097/BRS.0b013e318221b5af

3. Smith GW, Robinson RA. The treatment of certain cervical-spine disorders by anterior removal of the intervertebral disc and interbody fusion. J Bone Joint Surg Am. 1958;40A(3):607-624.

4. Chen F, He W, Mahaney K, et al. Alternative grafts in anterior cervical fusion. Clin Neurol Neurosurg. 2013;115(10):2049-2055. doi:10.1016/j.clineuro.2013.07.013

5. Maharaj MM, Phan K, Mobbs RJ. Anterior cervical discectomy and fusion (ACDF) autograft versus graft substitutes: what do patients prefer? - a clinical study. J Spine Surg. 2016;2(2):105-110. doi:10.21037/jss.2016.05.01

6. Park J-I, Cho D-C, Kim K-T, Sung J-K. Anterior cervical discectomy and fusion using a stand-alone polyetheretherketone cage packed with local autobone: assessment of bone fusion and subsidence. $J$ Korean Neurosurg Soc. 2013;54(3):189-193. doi:10.3340/jkns.2013.54.3.189

7. Gercek E, Arlet V, Delisle J, Marchesi D. Subsidence of stand-alone cervical cages in anterior interbody fusion: warning. Eur Spine J. 2003;12(5):513-516. doi:10.1007/s00586-0030539-6

8. Zajonz D, Franke A-C, von der Höh N, et al. Is the radiographic subsidence of stand-alone cages associated with adverse clinical outcomes after cervical spine fusion? An observational cohort study with 2-year follow-up outcome scoring. Patient Saf Surg. 2014;8(1):43. doi:10.1186/s13037-0140043-4

9. Kim JH, Park JY, Yi S, et al. anterior cervical discectomy and fusion alters whole-spine sagittal alignment. Yonsei Med. J. 2015;56(4):1060-1070. doi:10.3349/ymj.2015.56.4.1060

10. Yang JJ, Yu CH, Chang B-S, Yeom JS, Lee JH, Lee C$\mathrm{K}$. Subsidence and nonunion after anterior cervical interbody fusion using a stand-alone polyetheretherketone (PEEK) cage. Clin Orthop Surg. 2011;3(1):16-23. doi:10.4055/cios.2011.3.1.16

11. Kao T-H, Wu C-H, Chou Y-C, Chen H-T, Chen W-H, Tsou H-K. Risk factors for subsidence in anterior cervical fusion with stand-alone polyetheretherketone (PEEK) cages: a review of 82 cases and 182 levels. Arch. Orthop. Trauma Surg. 2014;134(10):1343-1351. doi:10.1007/s00402-014-2047-z

Disclosures and COl: The authors have no conflicts of interest to declare. No ethical approval was required.

Corresponding Author: Andrew P. MacCormick, BMBS, South West Neurosurgery Centre, Derriford Hospital, Derriford Road, Plymouth PL6 
8DH, United Kingdom. Phone: +447742454630; charge by ISASS, the International Society for the Email: andrew.maccormick@nhs.net.

Published 22 January 2021

Advancement of Spine Surgery. Copyright (C) 2020

This manuscript is generously published free of ISASS. To see more or order reprints or permissions, see http://ijssurgery.com. 